\title{
Changes in erythrocyte polyunsaturated fatty acids and plasma eicosanoids level in patients with asthma
}

\author{
Jing Zhou', Lifang Chen², Zhenjie Liư ${ }^{3}$, Ling Sang ${ }^{1}$, Yimin Li ${ }^{1}$ and Dongjuan Yuan ${ }^{4,5^{*}}$ (D)
}

\begin{abstract}
Background: To investigate the changes of polyunsaturated fatty acids (PUFAs) and their downstream eicosanoids in patients with asthma, the levels of erythrocyte membrane lipids and plasma lipid metabolites were examined.

Methods: Erythrocyte membrane lipids were extracted and esterificated, and then fatty acid compositions were determined by gas chromatography. The concentrations of six eicosanoids of $\mathrm{PGE}_{2}, \mathrm{TXA}_{2}, \mathrm{LTB}_{4}, \mathrm{PGE}, 6-\mathrm{k}-\mathrm{PGF} \mathrm{F}_{1 \alpha}$ and $\mathrm{PGF}_{2 a}$ in plasma were measured by ELISA.

Results: The results showed that the contents of erythrocyte membrane fatty acids in patients with asthma were mainly composed of C16:0, C18:0, C18:1, C18:2(n-6), and C20:4(n-6). The ratio n-6/n-3 PUFAs in patients and health persons were $(4.42 \pm 1.33): 1$ and $(3.21 \pm 0.79): 1(p<0.01)$, showing statistically significant differences. ELISA results showed that the levels of plasma $\mathrm{PGE}_{2}, \mathrm{TXB}_{2}$, and $\mathrm{PGE}_{1}$ in patients were higher than health persons; and the levels of eicosanoids of $\mathrm{PGF}_{2 a}$ and 6-k-PGF 1 were significantly lower in patient group than healthy group $(p<0.05)$, but $\mathrm{LTB}_{4}$ was no obvious difference $(p=0.09)$. Increased ratio of $n-6 / n-3$ PUFAs is consistent to the increased levels of pro-inflammatory $\mathrm{PGE}_{2}$ and $\mathrm{TXB}_{2}$ and anti-inflammatory $\mathrm{PGE}_{1}$ originated from $\mathrm{C} 20: 4(\mathrm{n}-6)$ and $\mathrm{C} 18: 2(\mathrm{n}-6)$, indicating that increased ratio of n-6/n-3 PUFAs and eicosanoids from n-6 PUFAs might promote the progress of airway inflammation of asthma.

Conclusion: Changes of erythrocyte fatty acids, n-6/n-3 PUFAs ratio and the levels of plasma $\mathrm{PGE}_{2}, \mathrm{TXB}_{2}$, and PGE in patients with asthma were relevant to airway inflammation in some extent. Therefore, it could be proposed that increase of n-3/n-6 PUFAs ratio by diet supplementation of n-3 PUFAs might effectively improve airway inflammation in asthma.
\end{abstract}

Keywords: Asthma, Polyunsaturated fatty acids, Eicosanoids, Inflammation

\section{Background}

Asthma is an allergic disease of the airways associated with airway hyperresponsiveness to various bronchoconstrictor stimuli $[1,2]$. The incidence of asthma has rapidly increased in China with the economic and industrial development in the last decades; this disease becomes one of the most common chronic diseases in China [3]. This epidemic trend has been regarded as correlation with lifestyle changes, such as hygiene, an indoor life, reduced physical activity, and a modified diet. There are some diet

\footnotetext{
* Correspondence: dongjuanyuan@foxmail.com

${ }^{4}$ College of Veterinary Medicine, South China Agricultural University, No.483

Wushan Rd, Guangzhou 510642, People's Republic of China

${ }^{5}$ Department of Biochemistry, Guangdong Medical University, Zhanjiang

524023, China

Full list of author information is available at the end of the article
}

hypothesis of an unbalance high intake of $n-6$ polyunsaturated fatty acids ( $\mathrm{n}-6$ PUFAs) such as linoleic acid (LA, C18:2) and arachidonic acid (AA, C20:4), may contribute to the incidence of allergic sensitization and asthma [4].

PUFAs are important components of cellular membrane and functional lipid mediators, which can be divided into n-6 PUFAs and n-3 PUFAs [4]. PUFAs can be metabolized into pro-inflammatory or anti-inflammatory mediators of prostaglandins (PGs), thromboxanes (TXs), leukotrienes (LTs), and lipoxins. These eicosanoids form a complex network to play a regulatory role in cell chemotaxis, inflammation, vascular permeability [4]. Airway inflammation is a common pathological feature of all types of asthma, which is characterized by airway epithelial injury, and results in morpho-functional modifications [2].

(C) The Author(s). 2018 Open Access This article is distributed under the terms of the Creative Commons Attribution 4.0 International License (http://creativecommons.org/licenses/by/4.0/), which permits unrestricted use, distribution, and reproduction in any medium, provided you give appropriate credit to the original author(s) and the source, provide a link to the Creative Commons license, and indicate if changes were made. The Creative Commons Public Domain Dedication waiver (http://creativecommons.org/publicdomain/zero/1.0/) applies to the data made available in this article, unless otherwise stated. 
In this study, we detected the composition of fatty acids in erythrocyte membrane and downstream eicosanoids in plasma including prostaglandin $\mathrm{E} 2\left(\mathrm{PGE}_{2}\right)$, prostaglandin E1 $\left(\mathrm{PGE}_{1}\right)$, thromboxane B2 $\left(\mathrm{TXB}_{2}\right)$, leukotriene B4 $\left(\mathrm{LTB}_{4}\right)$, prostaglandin $\mathrm{F} 1 \mathrm{a}\left(\mathrm{PGF}_{1 \mathrm{a}}\right)$, prostaglandin $\mathrm{F} 2 \mathrm{a}\left(\mathrm{PGF}_{2 \mathrm{a}}\right)$ (Fig. 1) in patients with asthma and healthy persons, so as to explore the changes of these lipids in asthma and elucidate their correlations.

\section{Methods}

\section{Subjects, study design}

Thirty-one subjects with physician-diagnosed asthma were recruited from the first affiliated hospital of Guangdong medical university. A group of healthy subjects were recruited from Blood center of Zhanjiang in Guangdong province. All subjects were recruited between March 2008 and September 2008. This study goal was to test the compositions of erythrocyte fatty acids and plasma eicosanoids in patients with asthma and healthy persons.

\section{Blood samples collection}

The blood samples were collected to separate the erythrocytes and stored at $-80{ }^{\circ} \mathrm{C}$ until analyses. Ten percent blinded duplicates were included for quality control purposes for fatty acids and eicosanoids' assays in blood.

\section{Fatty acid methylation}

$0.5 \mathrm{ml}$ of heparinized venous blood samples were centrifuged for $20 \mathrm{~min}$ in $3000 \mathrm{rpm} / \mathrm{min}$ at $4{ }^{\circ} \mathrm{C}$, and then the supernatants were removed in order to remove leukocytes and platelets. The lower layer cells were washed by double deionized water, and then centrifuged for $10 \mathrm{~min}$ in $3000 \mathrm{rpm} / \mathrm{min}$ to remove the supernatants. This was repeated three times to collect the lower layer of erythrocytes. In order to analyze the compositions of erythrocyte fatty acids, a simplified method for analysis of PUFAs was used to extract total lipids and fatty acid methylation [5]. One milliliter $(\mathrm{ml}) \mathrm{n}$-hexane and $1 \mathrm{ml} \mathrm{14 \%}$ boron trifluoride $\left(\mathrm{BF}_{3}\right) /$ methanol $(\mathrm{MeOH})$ (Sigma-Aldrich) were added to silica tube. Tricosanic acid (C17:0) (0.02 mg: $100 \mu \mathrm{l}$, $0.2 \mathrm{mg} / \mathrm{ml}$ ) was also added to each tube as internal standard. Air was purged with a gentle stream of nitrogen. Samples were methylated for $1 \mathrm{~h}$ at $100{ }^{\circ} \mathrm{C}$ and the reaction stopped with the addition of $1 \mathrm{ml}$ double deionized water. After centrifugation for $10 \mathrm{~min}$ at $3000 \mathrm{~g}$, the upper hexane layer containing the fatty acid methyl esters was transferred to a $2 \mathrm{ml} \mathrm{GC}$ vial [6].

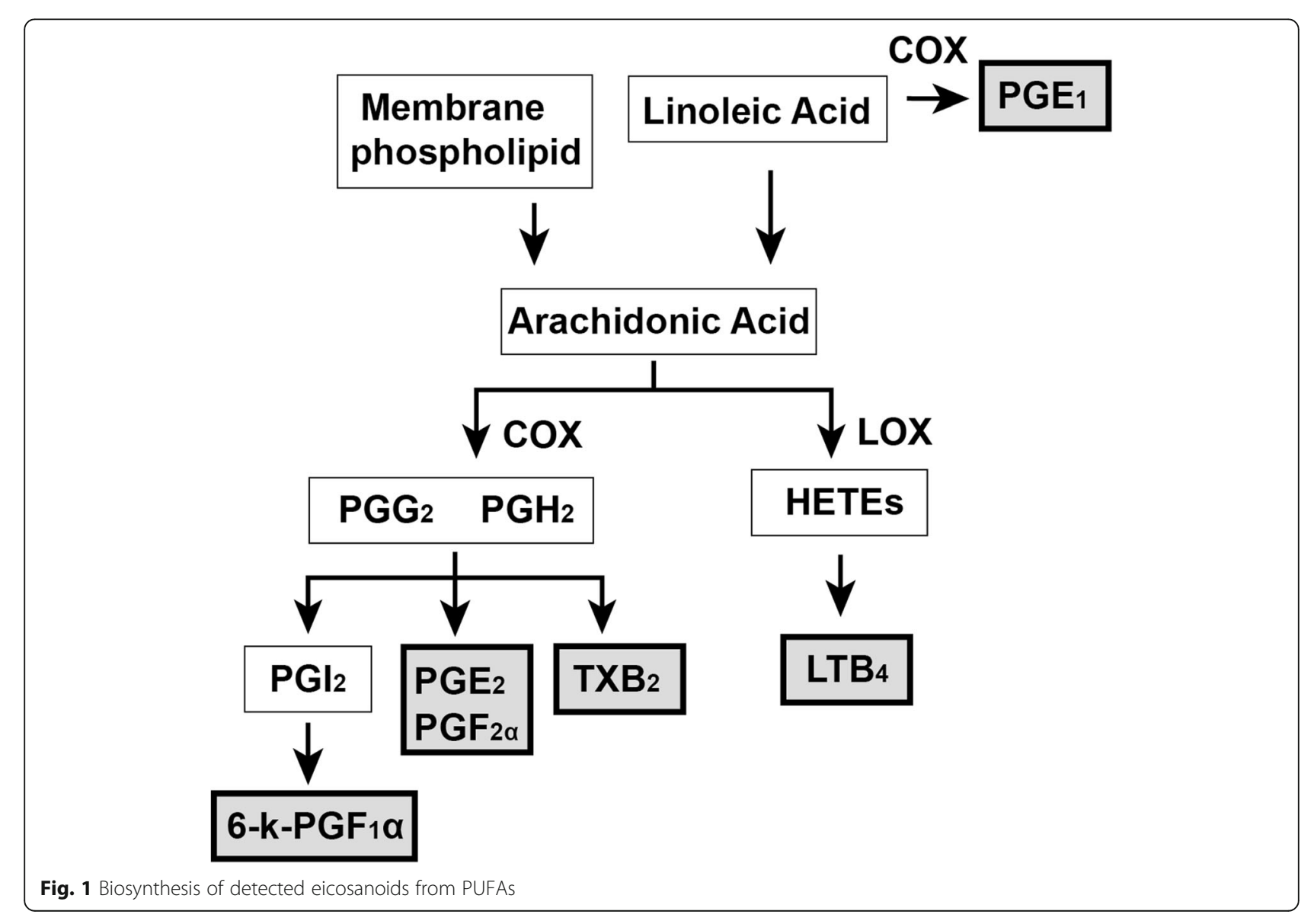




\section{GC analysis}

Fatty acid methyl esters were separated on a Shimadzu Scientific Instruments, GC-2010 gas chromatograph equipped with a flame ionization detector and $30 \mathrm{~m} \times$ $0.25 \mathrm{~mm} \times 0.25 \mathrm{~m}$ Omega-WAX capillary column (J\&W, Agilent). Helium was used as the carrier at a constant flow rate of $10.1 \mathrm{ml} / \mathrm{min}$. One microliter fatty acid methyl esters were injected into the column in split mode. Fatty acid methyl esters were eluted using a temperature program from 100 to $250{ }^{\circ} \mathrm{C}$. The initial temperature of $100{ }^{\circ} \mathrm{C}$ ramped to $220^{\circ} \mathrm{C}$ at $15{ }^{\circ} \mathrm{C} / \mathrm{min}$ and held for $12 \mathrm{~min}$, then ramped to $250{ }^{\circ} \mathrm{C}$ at $10{ }^{\circ} \mathrm{C} / \mathrm{min}$ and held for $13 \mathrm{~min}$. Fatty acid peaks were identified by comparing the retention time of each peak against the retention times of validated fatty acid standards (Supelco, Bellefonte, PA) (Fig. 2). Unidentified peaks were not included in the calculation of the percentage in total fatty acid [5, 6]. Values are expressed as \% total fatty acids, and total fatty acid concentration (nmol/g viscera) was calculated by comparison of gas chromatography peak areas relative to that of the C17:0 internal standard.

\section{Quantification of lipid mediators}

Six kinds of eicosanoids derived from C18:2 and C20:4 were detected. Immunoassays for $\mathrm{PGE}_{2}, \mathrm{PGE}_{1}, \mathrm{TXA}_{2}$, $\mathrm{LTB}_{4}, \mathrm{PGF}_{1 \mathrm{a}}$, and $\mathrm{PGF}_{2 \mathrm{a}}$ were performed in duplicate using the human $\mathrm{PGE}_{2}$ Quantikine ELISA kit, human $\mathrm{PGE}_{1}$ Quantikine ELISA kit, human TXA 2 Quantikine ELISA kit, human $\mathrm{LTB}_{4}$ Quantikine ELISA kit, human $\mathrm{PGF}_{1 \mathrm{a}}$ Quantikine ELISA kit, and human PGF 2 Q Quantikine ELISA kit (R\&D Systems), respectively. Plasma samples were assayed according to the manufacturer's instructions. Briefly, plasma samples and controls were added to ELISA plates pre-coated with the capture antibody, then incubated in $37{ }^{\circ} \mathrm{C}$ for $60 \mathrm{~min}$, washed and detected based on a colorimetric reaction between a horseradish peroxidase-labeled detection antibody and the tetramethyl benzidine substrate solution. The color absorbance at $450 \mathrm{~nm}$ was measured using a spectrophotometer (Bio-Rad).

\section{Statistical analysis}

T-test and one-way ANOVA analyses were used to evaluate differences in mean erythrocyte fatty acids and mean eicosanoids' concentrations. Spearman's correlation coefficient and partial correlation coefficient were used to describe the concentrations of erythrocyte fatty acid and plasma eicosanoids (Tables 1 and 2). Analyses were performed with SPSS 16.0, a $p<0.05$ was considered statistically significant.

\section{Results}

\section{Baseline}

Overall, 31 patients and 31 healthy persons were included in this study, with a mean age of $58 \pm 6.5$ years old (patients group) and $25 \pm 2.3$ years old (healthy group), respectively. In the patients group, there were 13 men (41.90\%), 5 patients in 27-29 years old (16.10\%), 9 in 30-39 years old (26.03\%), 5 in $40-49$ years old (16.10\%), 6 in $50-59$ years old (19.35\%), 5 in 60-69 years old (16.10\%), 1 in 70 79 years old $(3.22 \%)$. Meanwhile, the healthy group was 15 healthy men (48.4\%) who aged $>16$ years old, with no prior history of asthma or other respiratory diseases, allergic diseases, and other chronic diseases.

\section{Measured lipids}

Comparison of the contents of fatty acids in the erythrocyte membrane between patients group and healthy group was given in Table 1 . The compositions of erythrocyte saturated fatty acid (SFAs), PUFAs, and monounsaturated fatty acids (MUFAs) from patients with asthma were $41.70 \%, 38.05 \%$, and $20.26 \%$, respectively. In the healthy

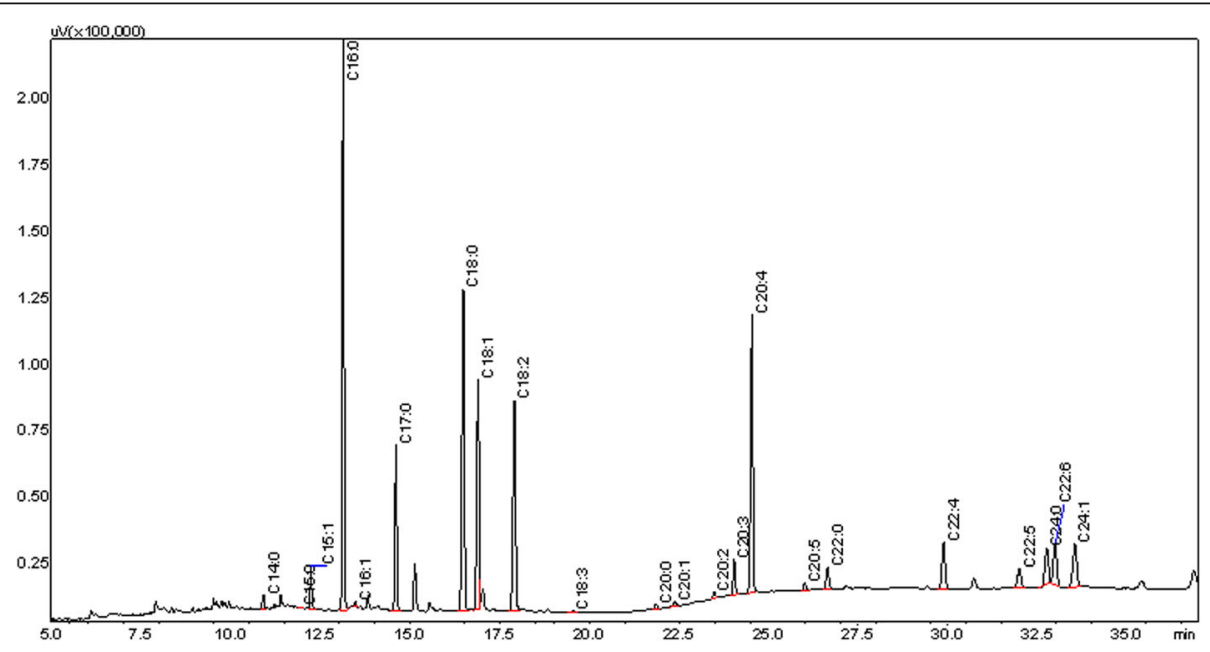

Fig. 2 Gas chromatogram of blood fatty acids in asthma patient 
Table 1 Comparison of fatty acid compositions in healthy persons and patients $(\%, X \pm S)$

\begin{tabular}{|c|c|c|}
\hline & Healthy group $(n=31)$ & Patients group $(n=31)$ \\
\hline$\overline{C 14: 0}$ & $0.30 \pm 0.25$ & $0.65 \pm 0.48^{* *}$ \\
\hline C15:0 & $0.10 \pm 0.04$ & $0.17 \pm 0.09$ \\
\hline C15:1 & $2.43 \pm 0.46$ & $1.95 \pm 0.44^{* *}$ \\
\hline C16:0 & $17.76 \pm 0.83$ & $19.74 \pm 2.12^{* *}$ \\
\hline C16:1 & $0.26 \pm 0.12$ & $0.51 \pm 0.17^{* *}$ \\
\hline C18:0 & $10.26 \pm 0.60$ & $10.43 \pm 0.69$ \\
\hline C18:1 & $12.14 \pm 1.23$ & $14.02 \pm 1.96^{* *}$ \\
\hline C18:2(n-6) & $10.69 \pm 1.24$ & $10.47 \pm 1.99$ \\
\hline C18:3(n-3) & $0.07 \pm 0.02$ & $0.09 \pm 0.07$ \\
\hline$C 20: 0$ & $0.32 \pm 0.05$ & $0.34 \pm 0.10$ \\
\hline C20:1 & $0.25 \pm 0.05$ & $0.27 \pm 0.08$ \\
\hline$C 20: 2(n-6)$ & $0.79 \pm 0.46$ & $0.30 \pm 0.13^{* *}$ \\
\hline$C 20: 3(n-6)$ & $1.37 \pm 0.30$ & $1.45 \pm 0.32$ \\
\hline$C 20: 4(n-6)$ & $16.52 \pm 1.07$ & $15.52 \pm 2.12^{*}$ \\
\hline C20:5(n-3) & $0.64 \pm 0.35$ & $0.73 \pm 0.41$ \\
\hline C22:0 & $4.86 \pm 1.93$ & $4.16 \pm 2.74$ \\
\hline$C 22: 4(n-6)$ & $2.96 \pm 0.54$ & $2.76 \pm 0.80$ \\
\hline$C 22: 5(n-3)$ & $2.25 \pm 0.40$ & $2.18 \pm 0.48$ \\
\hline$C 22: 6(n-3)$ & $7.57 \pm 1.52$ & $4.55 \pm 1.87^{* *}$ \\
\hline C24:0 & $4.24 \pm 1.03$ & $6.21 \pm 1.55^{*}$ \\
\hline C24:1 & $4.21 \pm 0.70$ & $3.51 \pm 1.12^{* *}$ \\
\hline$n-6$ & $32.33 \pm 1.57$ & $30.49 \pm 3.03^{* *}$ \\
\hline$n-3$ & $10.52 \pm 2.05$ & $7.56 \pm 2.37^{* *}$ \\
\hline$n-6 / n-3$ & $3.21 \pm 0.79$ & $4.42 \pm 1.33^{*}$ \\
\hline AA & 16.52 & 15.52 \\
\hline $\mathrm{EPA}+\mathrm{DHA}$ & 8.21 & 5.28 \\
\hline $\mathrm{AA} /(\mathrm{EPA}+\mathrm{DHA})$ & 2.01 & 2.94 \\
\hline SFA & 37.84 & 41.70 \\
\hline MUFA & 19.29 & 20.26 \\
\hline PUFA & 42.86 & 38.05 \\
\hline UFA & 62.15 & 58.31 \\
\hline SFA/UFA & 0.61 & 0.72 \\
\hline
\end{tabular}

Note: ${ }^{*}, p<0.05 ;{ }^{* *}, p<0.01$

group, the contents of SFAs, PUFAs, and MUFAs were $37.84 \%, 42.86 \%$, and $20.26 \%$, respectively. Hence, SFAs, mainly composed of $\mathrm{C} 16: 0$ and C18:0, were the most abundant fatty acids in patients group, while PUFAs, mainly composed of $C 18: 2(n-6)$ and $C 20: 4(n-6)$, were the most abundant components in healthy group. The percentages of C14:0, C16:0, and C24:0 in patients with asthma were $0.65 \pm 0.48,19.74 \pm 2.12$, and $6.21 \pm 1.55$, which was significantly higher than that of healthy persons of $0.30 \pm 0.25,17.76 \pm 0.83$, and $4.24 \pm 1.03$, respectively. Previous study also observed a significant accumulation of saturated fatty acids in chronic bronchitis and chronic obstructive pulmonary disease [7].

The percentages of $n-6$ and n-3 PUFAs in total erythrocyte fatty acids in patients were $30.49 \pm 3.03$ and $7.56 \pm$ 2.37, while in healthy group, the percentages of $n-6$ and $n-3$ PUFAs were $32.33 \pm 1.57$ and $10.52 \pm 2.05$, respectively. The contents of n- 6 and n-3 PUFAs were significantly decreased in patients group compared to the healthy group, while the ratio of $n-6 / n-3$ PUFAs in patients group were significantly higher than those in healthy group $(p<0.01)$.

In details, the difference of $n-6$ PUFAs of two groups was mainly due to the lower percentage of AA in patients group than that of healthy group. As for n-3 PUFAs, the percentages of EPA in patients group was as much as that in healthy group, while DHA in patients group was significantly lower than that in healthy group. Accordingly, the differences of n-3 PUFAs between two groups were mainly caused by the differences in DHA.

As shown in Table 2, the concentrations of $\mathrm{PGE}_{2}$, $\mathrm{TXB}_{2}$, 6-k-PGF ${ }_{1 \alpha}, \mathrm{PGF}_{2 \alpha}$ and $\mathrm{PGE}_{1}$ in patients group were significantly different to the healthy group. The levels of $\mathrm{PGE}_{2}, \mathrm{TXB}_{2}$, and $\mathrm{PGE}_{1}$ in patients group were higher than those in healthy group $(p<0.05)$, while the levels of $\mathrm{PGF}_{2 \alpha}$ and $6-\mathrm{k}-\mathrm{PGF}_{1 \alpha}$ in patient group were lower than the healthy group (Fig. 3). The concentrations of $\mathrm{LTB}_{4}$ was no significant difference between two groups $(p>0.05)$ (Fig. 3).

\section{Discussion}

Our study showed that erythrocyte fatty acids were mainly composed of C16:0, C18:0, C18:1, C18:2(n-6), and C20:4(n-6) in patients with asthma and healthy persons. The contents of fatty acids from the high to low were SFA, PUFA, and MUFA in patients group, respectively, while the healthy group was PUFA, SFA, and MUFA. The proportion of SFAs in erythrocytes in patients with asthma was higher than that in healthy persons. The contents of C14:0, C16:0, and C24:0 in patients were higher than healthy persons. It is known that accumulation of fatty acids due to altered metabolism could induce cell death, cytokine secretion and activation of inflammatory processes. SFAs have been described as ligands of Toll-like receptor 4 to induce fatty acid-mediated cytotoxicity by

Table 2 Comparison of the concentrations of 6 eicosanoids in healthy and patient groups ( $\mathrm{ng} / \mathrm{ml}, \mathrm{pg} / \mathrm{ml}$ for $\left.L T B_{4}, X \pm S\right)$

\begin{tabular}{lllllll}
\hline & $\mathrm{PGE}_{2}(n=31)$ & $\mathrm{TXB}_{2}(n=30)$ & $\mathrm{LTB}_{4}(n=30)(\mathrm{pg} / \mathrm{ml})$ & $\mathrm{PGE}_{1}(n=31)$ & $6-\mathrm{k}_{\mathrm{PGF}}(n=28)$ & $\mathrm{PGF} 2 \mathrm{a}(n=22)$ \\
\hline Healthy group & $5.09 \pm 1.47$ & $4.28 \pm 0.58$ & $2.78 \pm 0.56$ & $2.96 \pm 0.46$ & $1.40 \pm 0.63$ & $1.84 \pm 0.84$ \\
Patients group & $5.99 \pm 0.87^{* *}$ & $4.88 \pm 0.89^{* *}$ & $3.02 \pm 0.64$ & $4.54 \pm 0.48^{* *}$ & $0.94 \pm 0.36^{* *}$ & $1.11 \pm 0.73^{*}$ \\
\hline Note: ${ }^{*}, p<0.05 ;{ }^{* *}, p<0.01$ & & & &
\end{tabular}

Note: ${ }^{*}, p<0.05 ; * *, p<0.01$ 


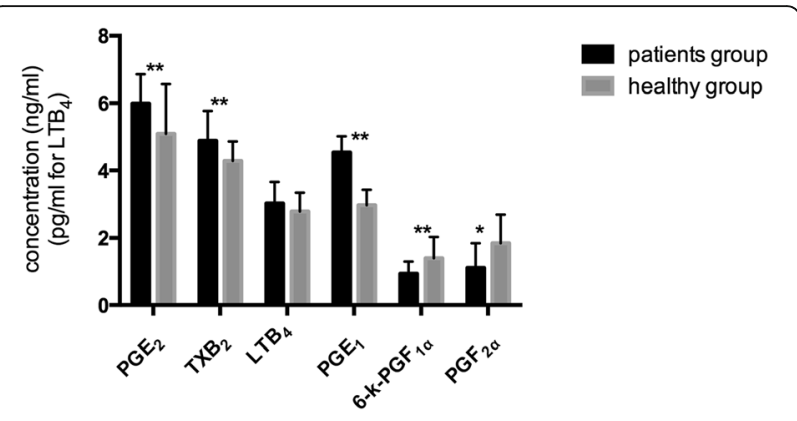

Fig. 3 Comparison of the concentrations of 6 eicosanoids in healthy and patient groups ( $\mathrm{ng} / \mathrm{ml}, \mathrm{pg} / \mathrm{ml}$ for $\mathrm{LTB}_{4}, \mathrm{X} \pm \mathrm{S}$ )

activation of nuclear factor kappa B and C-jun $\mathrm{N}$-terminal kinase in murine macrophages and adipocytes [8-11]. Accumulation of SFAs can activate organellar dysfunctions of lysosomal destabilization [12-14] and endoplasmic reticulum stress [15-17] via the intrinsic apoptosis pathway and activation of death receptors of tumor necrosis factor (TNF) receptors and TNF-related apoptosis inducing ligand-receptors via extrinsic apoptotic pathways $[18,19]$. C24:0 has also been described to stimulate NADPH oxidase activity to enhance lipid peroxidation in fibroblasts [20]. Thus, the increased level of SFAs, especially C14:0, C16:0, and C24:0, might be associated with the inflammatory responses of asthma.

PUFAs could exert various functions through directly mechanisms or their metabolites. In this study, the proportion of PUFAs in erythrocytes in patients with asthma was lower than that in healthy persons, indicating that increased consumption of PUFAs in asthma might induce the lower level of PUFAs in patients than the healthy persons. As for the significantly difference $(58 \pm 6.5$ vs $25 \pm$ 2.3) in ages from two groups in this study, a number of clinical trials, including patients with asthma, have investigated the changs in the ratio of $n-3 / n-6$ PUFAs ranged from 3 to 72 years old, showing that the age may not influence the results of study [4]. Our data showed that the ratio of n-6 PUFA/n-3 PUFAs (4.42 $\pm 1.33: 1)$ in erythrocyte in patients with asthma was significantly higher than that in healthy persons $(3.21 \pm 0.79: 1)(p<0.01)$. n-6 PUFAs could regulate the inflammatory responses of the body by their metabolites [4]. n-3 PUFAs (mainly EPA and DHA) could competitively inhibit the oxidation of $n-6$ PUFAs by COX or LOX and reduce the production of eicosanoids from n-6 PUFAs [2, 4]. Observational studies and clinical trials have showed that intake of $n-3$ PUFAs with fish oil supplementation have the protective effect on exercise-induced bronchoconstriction in asthma $[21,22]$. Therefore, our data of higher ratio of $n-6 / n-3$ PUFAs is consistent to these clinical trials, indicating that the higher ratio of $n-6 / n-3$ PUFAs could partially reflect the inflammatory status of asthma.
PUFAs could be metabolized to PGs, TXs, and LTs through COX and LOX pathways to involve in regulating inflammatory responses [23]. In our study, the concentration of pro-inflammatory mediators of $\mathrm{PGE}_{2}$ and $\mathrm{TXB}_{2}$ produced by the action of COX on AA are the predominant pro-inflammatory eicosanoids, were higher in asthma patients than that in healthy persons (Table 2) but $6-\mathrm{K}_{-} \mathrm{PGF}_{1 \alpha}$ was lower in patients than that in healthy persons. It is consistent to previous study of the higher level of $\mathrm{PGE}_{2}$ and $\mathrm{TXB}_{2}$ in the plasma of asthma patients than that of healthy persons, and the concentration of 6-K-PGF $1 \alpha$ in patients was lower than healthy persons [24]. $\mathrm{LTB}_{4}$, the downstream metabolites of AA produced by the action of 5-LOX, has been considered as a pro-inflammatory mediator and induce airway hyper-reactivity $[25,26]$. $\mathrm{LTB}_{4}$ in BALF fluid or blood from severe asthma were higher than moderate symptomatic asthma patients and normal [27, 28]. However, the concentration of $\mathrm{LTB}_{4}$ in two groups showed no statistical difference in this study. $\mathrm{PGF}_{2 \alpha}$ have been also demonstrated to be involved in acute or chronic inflammation in several situations such as asthma [26]. In this study, the concentration of $\mathrm{PGF}_{2 \alpha}$ in patients was lower than the healthy group. Furthermore, the concentration of $\mathrm{PGE}_{1}$, a typical anti-inflammatory factor, was also higher in asthma patients than that in healthy persons. $\mathrm{PGE}_{1}$ could dilate blood vessels, inhibit oxygen radicals and macrophage activation [3]. Our data showed that the relationship between PUFAs and their downstream metabolites were consistent with inflammation.

Asthma is a complex syndrome with different clinical phenotypes, airway inflammation is a response companied with the pro-inflammatory and anti-inflammatory reactions in the body. In the initial stage of airway inflammation, the contents of pro-inflammatory mediators might be high, while with the progress of inflammatory responses, the contents of anti-inflammatory mediators were also produced to involve in inflammatory responses. Eicosanoids of $\mathrm{PGE}_{2}, \mathrm{TXB}_{2}$, and $\mathrm{PGE}_{1}$ might be the potential biomarkers associated with the inflammatory responses of asthma, and the treatment of asthma using n-3 PUFAs may be useful to improve the symptoms of asthma [4].

\section{Conclusions}

In conclusion, we investigated the compositions of erythrocyte fatty acids and plasma eicosanoids in patients with asthma from Zhanjiang. Changes in fatty acids and eicosanoids level, especially the higher level of $\mathrm{PGE}_{2}, \mathrm{TXB}_{2}, \mathrm{PGE}_{1}$, and the ratio of $\mathrm{n}-6 / \mathrm{n}-3$ PUFAs in patients with asthma than healthy persons, might be due to the airway inflammation. It provides the basis for studying the association of fatty acids and its metabolites with airway inflammation of asthma. 


\section{Abbreviations}

AA: Arachidonic acid; ALA: a linolenic acid; DHA: Docosahexaenoic acid; DPA: Docosapentaenoic acid; EPA: Eicosapentaenoic acid; LA: Linolenic acid LTB4: Leukotriene B4; MUFA: Monounsaturated fatty acid; PUFA: Polyunsaturated fatty acid; SFA: Saturated fatty acid

\section{Acknowledgments}

We thank Prof. Jingxuan Kang (Massachusetts General Hospital, Harvard University), Prof. Keyuan Zhou (Guangdong Medical University), Prof. Liming Jiang (Guangdong Medical University) for comments, reagents, discussions and data analysis.

\section{Funding}

This study was financially supported by medical health and technology project of Guangzhou (Grant No. 20161A011061), National natural science foundation of China (No. 81770079) and Guangdong provincial science and technology department (No. 2016A020215136).

\section{Authors' contributions}

JZ wrote the paper and analyzed the data. Lifang Chen, Sang Ling and Zhenjie Liu collected the samples. YL provided some writing suggestions on the paper. DY designed the experiments, analyzed the data, and wrote the paper. All authors read and approved the final manuscript.

\section{Ethics approval and consent to participate}

This study was reviewed and approved by the medical ethics committee of the first affiliated hospital of Guangzhou Medical University (No. 2017-04) and all patients and healthy persons included in this study provided written informed consent.

\section{Consent for publication}

All patients and healthy persons included in this study provided written informed consent.

\section{Competing interests}

The authors declare that they have no competing interests.

\section{Publisher's Note}

Springer Nature remains neutral with regard to jurisdictional claims in published maps and institutional affiliations.

\section{Author details}

${ }^{1}$ Department of Respiratory and Critical Care Medicine, the First Affiliated Hospital of Guangzhou Medical University, Guangzhou Institute of Respiratory Health, Guangzhou 510120, China. 'Department of Respiratory, The affiliated hospital of Guangdong medical University, Zhanjiang 524023, China. ${ }^{3}$ The Second Affiliated Hospital of Guangdong University of Chinese Medicine, Guangzhou 510120, China. ${ }^{4}$ College of Veterinary Medicine, South China Agricultural University, No.483 Wushan Rd, Guangzhou 510642, People's Republic of China. ${ }^{5}$ Department of Biochemistry, Guangdong Medical University, Zhanjiang 524023, China.

Received: 26 April 2018 Accepted: 23 August 2018 Published online: 01 September 2018

\section{References}

1. Ishmael FT. The inflammatory response in the pathogenesis of asthma. J Am Osteopath Assoc. 2011;111:S11.

2. Barnes PJ, Drazen JM: Asthma and COPD: basic mechanisms and clinical management. 2002

3. Rogerio ADP, Sorgi CA, Sadikot R, Carlo T. The role of lipids mediators in inflammation and resolution. Biomed Res Int. 2014;2014:605959.

4. Wendell SG, Baffi C, Holguin F. Fatty acids, inflammation, and asthma. J Allergy Clin Immunol. 2014;133:1255-64.

5. Wang J, Kang JX. A simplified method for analysis of polyunsaturated fatty acids. BMC Biochem. 2005:6:1-4.

6. Yuan D, Zou Q, Yu T, Song C, Huang S, Chen S, Ren Z, Xu A. Ancestral genetic complexity of arachidonic acid metabolism in Metazoa. Biochim Biophys Acta. 1841;2014:1272-84.
7. Novgorodtseva TP, Denisenko YK, Zhukova NV, Antonyuk MV, Knyshova W, Gvozdenko TA. Modification of the fatty acid composition of the erythrocyte membrane in patients with chronic respiratory diseases. Lipids in Health \& Disease. 2013;12:117.

8. Shi H, Kokoeva MV, Inouye K, Tzameli I, Yin H, Flier JS. TLR4 links innate immunity and fatty acid-induced insulin resistance. J Clin Invest. 2006;116: 3015-25.

9. Lee HK, Dunzendorfer S, Tobias PS. Cytoplasmic domain-mediated dimerizations of toll-like receptor 4 observed by beta-lactamase enzyme fragment complementation. J Biol Chem. 2004;279:10564-74.

10. Suganami T, Tanimotokoyama K, Nishida J, Itoh M, Yuan X, Mizuarai S, Kotani H, Yamaoka S, Miyake K, Aoe S. Role of the toll-like receptor 4/NFkappaB pathway in saturated fatty acid-induced inflammatory changes in the interaction between adipocytes and macrophages. Arterioscler Thromb Vasc Biol. 2007:27:84-91.

11. Kennedy A, Martinez K, Chuang CC, Lapoint K, Mcintosh M. Saturated fatty acid-mediated inflammation and insulin resistance in adipose tissue: mechanisms of action and implications. J Nutr. 2009:139:1-4.

12. Feldstein AE, Werneburg NW, Canbay A, Guicciardi ME, Bronk SF, Rydzewski $R$, Burgart $L$, Gores GJ. Free fatty acids promote hepatic lipotoxicity by stimulating TNF-alpha expression via a lysosomal pathway. Hepatology. 2004:40:185-94.

13. Feldstein AE, Werneburg NW, Li Z, Bronk SF, Gores GJ. Bax inhibition protects against free fatty acid-induced lysosomal permeabilization. Am J Physiol Gastrointest Liver Physiol. 2006;290:1339-46.

14. $Z \mathrm{~L}, \mathrm{M} B, T M M, G J G, A E F$. The lysosomal-mitochondrial axis in free fatty acid-induced hepatic lipotoxicity. Hepatology. 2008;47:1495-503.

15. Wei Y, Wang D, Topczewski F, Pagliassotti MJ. Saturated fatty acids induce endoplasmic reticulum stress and apoptosis independently of ceramide in liver cells. Am J Physiol Endocrinol Metab. 2006;291:E275.

16. Pfaffenbach KT, Gentile CL, Nivala AM, Wang D, Wei Y, Pagliassotti MJ. Linking endoplasmic reticulum stress to cell death in hepatocytes: roles of C/EBP homologous protein and chemical chaperones in palmitatemediated cell death. Am J Physiol Endocrinol Metab. 2010;298:E1027.

17. Wei Y, Wang D, Gentile CL, Pagliassotti MJ. Reduced endoplasmic reticulum luminal calcium links saturated fatty acid-mediated endoplasmic reticulum stress and cell death in liver cells. Mol Cell Biochem. 2009:329:183-4.

18. Feldstein AE, Canbay A, Guicciardi ME, Higuchi H, Bronk SF, Gores GJ. Diet associated hepatic steatosis sensitizes to Fas mediated liver injury in mice. J Hepatol. 2003;39:978-83.

19. Malhi H, Barreyro FJ, Isomoto H, Bronk SF, Gores GJ. Free fatty acids sensitise hepatocytes to TRAIL mediated cytotoxicity. Gut. 2007:56:1124.

20. Dhaunsi GS, Kaur J, Alsaeid K, Turner RB, Bitar MS. Very long chain fatty acids activate NADPH oxidase in human dermal fibroblasts. Cell Biochem Funct. 2005;23:65-8

21. Mickleborough TD, Murray RL, Ionescu AA, Lindley MR. Fish oil supplementation reduces severity of exercise-induced bronchoconstriction in elite athletes. Am J Respir Crit Care Med. 2003;168:1181-9.

22. Mickleborough TD, Lindley MR, lonescu AA, Fly AD. Protective effect of fish oil supplementation on exercise-induced bronchoconstriction in asthma. Chest. 2006;129:39-49.

23. Miyata J, Arita M. Role of omega-3 fatty acids and their metabolites in asthma and allergic diseases. Allergol Int. 2015;64:27.

24. Kurosawa M, Kobayashi H, Kobayashi S. Plasma prostaglandin levels from bronchial asthmatic patients assayed by 9-Anthryldiazomethane-HPLC method. J Asthma. 1990;27:349-58.

25. Yokomizo T, Kato K, Kan T, Izumi T, Shimizu T. A Second Leukotriene B4 Receptor, Blt2. J Exp Med. 2000;192:421-32.

26. Barnes PJ, Chung KF, Page CP. Inflammatory mediators of asthma: an update. Pharmacol Rev. 1998;50:515-96.

27. Bhavsar PK, Levy BD, Hew MJ, Pfeffer MA, Kazani S, Israel E, Chung KF. Corticosteroid suppression of lipoxin A4 and leukotriene B4from alveolar macrophages in severe asthma. Respir Res. 2010;11:71.

28. Wenzel SE, Szefler SJ, Leung DY, Sloan SI, Rex MD, Martin RJ. Bronchoscopic evaluation of severe asthma. Persistent inflammation associated with high dose glucocorticoids. Am J Respir Crit Care Med. 1997:156:737-43. 